\title{
Older Adults Vs Middle-Aged Adults: Step Length
}

\author{
Sukwon Kim \\ Department of Physical Education, Jeonbuk National University, Jeonju, Jellabuk-do, South Korea \\ Correspondence should be addressed to Sukwon Kim; rockwall@jbnu.ac.kr
}

Copyright ( 2021 Made Sukwon Kim. This is an open access article distributed under the Creative Commons Attribution License, which permits unrestricted use, distribution, and reproduction in any medium, provided the original work is properly cited.

\begin{abstract}
The objective of the present study was to evaluate step length of middle-aged adults and older adults. Ten adults (14 middle age adults and 14 older adults) were recruited from a local community. They were all physically healthy and not injured in the last 6 months. One marker was placed on each heel (right and left heels) and the position data were collected during subsequent 5-minute walking on a straight track (15m long). The results indicated that step length of middle-age adults were larger than that of older adults during their natural gait. The study concluded that middle-age adults would likely to be involved in slips and falls.
\end{abstract}

KEYWORDS- Step Length, Middle age, Older, Falls

\section{INTRODUCTION}

Age-related gait characteristics and poor postural control are a major cause for slips and falls among older adults [1]. Slips and falls were major health hazards that threatened the quality of their life [1].

A person experienced a fall tended to curtail their habits or daily activities and, as a result, it caused functional and physical declines, and large economic and personal losses [1]. Heel contact velocity, center of mass (COM) velocity, required coefficient of friction (RCOF), step length, and muscle weakness were suggested to be major factors that increased the likelihood of slips and falls [2]. Middle age adults' muscle strength was similar to that of older adults, but, lower than that of younger adults [3]. The study [3] suggested that middle-aged adults could be at a higher risk of musculoskeletal injuries. However, a different study [4] suggested that older adults' muscular strength was lower than that of middle-aged adults. Muscular strength degradation may be associated with reduced functional and physical capabilities [5]. Muscular strength reduction may be associated with the likelihood of slips and falls [6]. In the previous research $[7,8]$ and middle-aged adults were susceptible to heel contact velocity and COM velocity have been studied in older adults and middle-aged adults. Yet, step length is not evaluated. The present study was to compare step length of older adults to that of middle-age

\section{METHOD}

\section{A. Participants}

The subjects of the present study $(n=28)$ were recruited from local community. Fourteen subjects were older adults and another 14 subjects were middle-age adults. They did not indicate previous injuries in the lower extremity in the past 6 months. They were included if they indicated no history of musculoskeletal injuries in the past 6 months. Older adults were all over 65 years of age and middle-age adults ranged from 40 to 51 years of age (Table 1).

Table 1: Age, Height, Weight of Two Groups (Mean (SD)

\begin{tabular}{|c|c|c|c|}
\hline Group & Age(years) & Height $(\mathrm{cm})$ & Weight $(\mathrm{kg})$ \\
\hline & 44.5 & 170.87 & 80.15 \\
Middle-age & $(3.90)$ & $(7.21)$ & $(17.62)$ \\
\hline & 70.6 & 168.49 & 72.58 \\
Older & $(3.67)$ & $(9.09)$ & $(16.30)$ \\
\hline
\end{tabular}

\section{B. Procedure}

Two heel markers were placed on the skin at anatomically significant landmarks to monitor heel-to-heel distances. Participants were asked to walk at their preferred walking speed by standing with feet together at either side of the walking track (15m long). Heel-to-heel distances were measured as step lengths. A gait cycle was defined from the first heel contact to the second heel contact of the right foot. Step lengths during a gait cycle were averaged and step lengths during 5 gait cycles were averaged for data analysis.

The position data of the markers were detected by eight-camera Prime 17W system (Natural Point, Inc, DBA Optitrack). Kinematic data (markers' locations) were sampled and recorded at $120 \mathrm{~Hz}$.

They were instructed to walk for about 5 minutes at their natural speed. Actual data collection started after 2 minutes of walking.

\section{Step Length}

The linear distance between the heel markers was calculated in the direction of progression between successive points of foot-to-floor contact of the first foot (X1, Y1) and other foot (X2, Y2). 


\section{RESULTS}

One-way ANOVA results suggested that there was a significant difference $(\mathrm{p}<0.01, \mathrm{~F}=12.87)$ in step length between older adults and middle-age adults. The results indicated that step length in middle age adults was larger than that in older adults (Table 2).

Table 2: Data and ANOVA Summary in Step Length of Two Groups

\begin{tabular}{|c|c|c|c|}
\hline \multicolumn{4}{|c|}{ Data Summary $(\mathbf{c m})$} \\
\hline Groups & N & Mean & SD \\
\hline Middle-Age Adults & 14 & 70.42 & 6.55 \\
\hline Older Adults & 14 & 61.39 & 6.76 \\
\hline
\end{tabular}

\begin{tabular}{|c|c|c|c|c|c|}
\hline \multicolumn{6}{|c|}{ ANOVA Summary } \\
\hline Source & $\begin{array}{c}\begin{array}{c}\text { Degrees } \\
\text { of } \\
\text { Freedom }\end{array} \\
\text { DF }\end{array}$ & $\begin{array}{c}\text { Sum of } \\
\text { Squares } \\
\text { SS }\end{array}$ & $\begin{array}{c}\text { Mean } \\
\text { Square } \\
\text { MS }\end{array}$ & F-Stat & P-Value \\
\hline $\begin{array}{l}\text { Between } \\
\text { Groups }\end{array}$ & 1 & 571.11 & 571.11 & 12.87 & 0.001 \\
\hline $\begin{array}{l}\text { Within } \\
\text { Groups }\end{array}$ & 26 & 1153.43 & 44.36 & & \\
\hline Total: & 27 & 1724.54 & & & \\
\hline
\end{tabular}

\section{DISCUSSION}

The study objective was to evaluate step length of middle age adults and older adults while walking on the leveled floor.

Previous studies reported that step lengths associated with walking velocity and RCOF would influence the likelihood of slips due to their effects on the horizontal shear force component (i.e. RCOF) at heel contact phase [6,9]. It was suggested that shorter step length has been thought to provide a stable gait contributing to a decreased RCOF $[10,11]$. In other words, increasing the step length would, in general, increase RCOF [12,13]. A previous study [3] reported that lower extremity strength of middle age adults was similar to that of older adults. The results from the previous study [3] gave a great insight into running the present study. In the present study, the results suggested that larger step length of middle-age adults with lower muscular strength could allow us to speculate that middle-age adults may be at a higher risk of falls compared to older adults.

\section{CONCLUSION}

The study concluded that middle age adults' step lengths were larger than that of older adults.

\section{RESEARCH QUESTION}

1. What will be other factors influencing the likelihood of slips and falls besides step length in middle age adults?

2. Why middle-age adults' step length is larger than older adults?

3. Will Larger step length in middle age adults increase the likelihood of slips and falls?

\section{ACKNOWLEDGEMENT}

This research was supported by "Research Base Construction Fund Support Program" funded by Jeonbuk National University in 2020 2021.

\section{CONFLICTS OF INTEREST}

The authors declare that they have no conflicts of interest.

\section{REFERENCES}

[1] H. Huang, M. Gau, W. Lin, and Kernohan, Assessing risk of falling in older adults. Public Health Nursing 20:5;399-411.

[2] J. Judge, 2003, Balance training to maintain mobility and prevent disability, Am J Prev Med, 25, 150-156.

[3] Kim S, Lockhart T, Nam C, 2010, Leg strength comparison between younger and middle-age adults, 40 , 315-320.

[4] Lindle, R., Metter, E.J., Lynch, N.A., Fleg, J.L., Fozard, J.L., Tobin, J., Roy, T.A., Hurley, B.F., 1997. Age and gender comparisons of muscle strength in 654 women and men aged 20-93 yr. Journal of Applied Physiology 83 (5), 1581-1587.

[5] Zhang, X, Buhr, T, 2002, Are back and leg muscle strength determinatens of lifting motion strategy? Insight from studying the effects of simulated leg muscle weakness. IJIE, 29(3), 161-169.

[6] Lockhart T, J. Smith, J. Woldstad, 2005, Effects of aging on the biomechanics of slips and falls Human Factors, 47(4), 708-729

[7] Kim S. 2020, Older adults vs middle-aged adults: walking velocity. IJIRCST, 8(5), 341-343.

[8] Kim S. 2020, Older adults vs middle-aged adults: heel velocity. IJIRCST, 8(4), 283-284.

[9] C. Irvine, 1986. Evaluation of the effect of contact-time when measuring floor slip resistance, Journal of Testing and Evaluation, 1, 19-22.

[10] S. Kim, T. Lockhart10\% front load carriage on the likelihood of slips and falls Industrial Health, 46 (2008), 32-39

[11] Myung et al., 1992

[12] Kim S., Lockhart T., Yoon H., 2005, Relationship between age-related gait adaptation and required coefficient of friction, Safety Science, 43, 425-436.

[13] Gro "nqvist, R., Roine, J., Jarvinen, E., Korhonen, E., 1989. An apparatus and a method for determining the slip resistance of shoes and floors by simulation of human foot motions. Ergonomics 32 (8), 979-995.

\section{ABOUT THE AUTHOR}

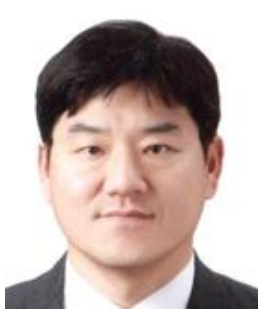

Dr. Sukwon Kim is a Professor of Department of Physical Education at Jeonbuk National University,Jeonju, South Korea. His main areas of research include Slips and Falls,Sport Biomechanics, Human factors, and Industrial Ergonomics. 